\title{
"Where to put your money to get their money: a bank advertising awareness study"
}

\begin{tabular}{|c|c|}
\hline AUTHORS & $\begin{array}{l}\text { James B. Bexley } \\
\text { Karen Sherrill }\end{array}$ \\
\hline ARTICLE INFO & $\begin{array}{l}\text { James B. Bexley and Karen Sherrill (2017). Where to put your money to get their } \\
\text { money: a bank advertising awareness study. Banks and Bank Systems, } 12(1-1) \text {, } \\
\text { 152-159. doi:10.21511/bbs.12(1-1).2017.08 }\end{array}$ \\
\hline DOI & http://dx.doi.org/10.21511/bbs.12(1-1).2017.08 \\
\hline RELEASED ON & Wednesday, 26 April 2017 \\
\hline RECEIVED ON & Monday, 19 December 2016 \\
\hline \multirow[t]{2}{*}{ ACCEPTED ON } & Wednesday, 08 February 2017 \\
\hline & $((c))$ EY-NC \\
\hline LICENSE & $\begin{array}{l}\text { This work is licensed under a Creative Commons Attribution-NonCommercial } 4.0 \\
\text { International License }\end{array}$ \\
\hline JOURNAL & "Banks and Bank Systems" \\
\hline ISSN PRINT & $1816-7403$ \\
\hline ISSN ONLINE & $1991-7074$ \\
\hline PUBLISHER & LLC “Consulting Publishing Company "Business Perspectives" \\
\hline FOUNDER & LLC “Consulting Publishing Company "Business Perspectives" \\
\hline & $\begin{array}{l}\text { E=- } \\
= \pm=\end{array}$ \\
\hline NUMBER OF REFERENCES & NUMBER OF FIGURES \\
\hline 10 & 3 \\
\hline
\end{tabular}

(c) The author(s) 2023. This publication is an open access article. 
James B. Bexley (USA), Karen Sherrill (USA)

\title{
Where to put your money to get their money: a bank advertising awareness study
}

\begin{abstract}
Commercial banks have many options when selecting an advertising medium. Where should a bank put its money in order to obtain the highest return? Should this medium change based on the target audience? This paper examines a number of different mediums for bank advertising and analyzes by age and by gender the efficacy of each. The authors administered a survey to over three hundred participants of varying ages asking them if they have seen bank advertisements on television, social media or the internet, billboards, traditional print media, or heard bank advertising on the radio. The survey, then, asks, if so, did it leave a favorable or unfavorable impression. Finally, the participants are asked to rank the mediums in terms of most favored to least favored. The authors find that television is the most effective medium. It reaches the broadest audience and the message is received favorably the largest percent of the time. The results show differences by age groups that can be beneficial to banks that are attempting to increase brand awareness and capture greater market share from particular age groups. For example, social media advertising works better for communicating with the younger age groups than the older age groups, however, it is still neither as effective nor as positively received as television.
\end{abstract}

Keywords: consumer, banking, services, preferences, marketing, advertising.

JEL Classification: G21.

Received on: 19th of December, 2016.

Accepted on: 8th of February, 2017.

\section{Introduction}

With all the options available for advertising today, what is the best venue for a bank to use? Are traditional venues appropriate for attracting older customers, whereas unconventional methods are required in order to attract younger generations? As banks strive to attract more millennials, it is important to understand how to reach them via advertising. Traditional marketing tools may be less effective for a generation raised with the internet and social media.

This paper examines the results of a survey where participants were asked to indicate if they recalled seeing advertisements for banks in five different types of advertising venues and if the advertising left a favorable or unfavorable impression. We examine attitudes towards television, social media, radio, billboards, and traditional print media. We, then, test if there are differences between age groups, between genders, and between genders within an age range.

\section{Literature review}

In reviewing the literature, there is an overabundance of how, when, and where to advertise, and what advertising is or is not. However, there is an absence of literature on the issues presented in this study examining

\footnotetext{
(C) James B. Bexley, Karen Sherrill, 2017.

James B. Bexley, Ph.D., Distinguished Professor of Finance and Chair Smith-Hutson Endowed Chair of banking, Sam Houston State University, USA.

Karen Sherrill, Ph.D., Assistant Professor, Department of General Business and Finance, Sam Houston State University, USA.

This is an Open Access article, distributed under the terms of the Creative Commons Attribution-NonCommercial 4.0 International license, which permits re-use, distribution, and reproduction, provided the materials aren't used for commercial purposes and the original work is properly cited.
}

the bank advertising by age and by gender, examining the efficacy of each. The only study found relating to age and gender was a Nielsen study (2015) and was limited to millennials only.

One of the earlier proponents of advertising, Mac Gregor (1913) noted that there is a wide variety of places for banks to advertise and plans that could be successful. Sharp (2010) found that advertising is a constant source to assist in recall. He also noted that advertising leads to sales through empirical studies, even though it is difficult if you just look at sales data. Franzen and Moriarty (2009) indicated that consumers are influenced by their environment, both off-line and on-line when it comes to their reaction to advertising.

Morrall (1995) stressed that image advertising was critical to any marketing strategy, because it is the best way to tell the consumer about the availability of products and services. Further, she noted that too many organizations try to avoid advertising. Cook (2011) expressed the need for good advertising message to separate their products, services, and practices, and to make the consuming public aware of the strengths of the bank's services as well as making the public aware of the differences between banks and their services.

Nielsen (2012) stated that "Global Trust in Advertising Survey of more than 28,000 Internet respondents in 56 countries shows that while nearly half $(47 \%)$ of consumers around the world say they trust paid television, magazine and newspaper ads, confidence declined by 24 percent, 20 percent and 25 percent, respectively, since 2009. Still, the majority of advertising dollars are spent on traditional or paid media, such as television". 
Making a case for social media communication, Keller and Fay (2012) indicated its importance, but they found that a balance between conventional media and social media is indicated. Research by Nelson-Field et al. (2012) found that the value of advertising through Facebook was questionable. Perhaps, balance in advertising is indicated after all.

The ABA Marketing \& Sales Journal (2014) found that it was virtually impossible to increase bank's core deposits without extensive advertising. It also noted that one bank surveyed by them used a combination of incentives and image advertising.

To summarize this review, Schultz (2014) presents an interesting "take" on the state of advertising. He noted that in today's age of data, we know everything we need to know to focus on the best means to reach the consuming public, but he believes that the fear of change prevents the advance of using all of this total data.

Our paper analyzes the efficacy of the different advertising mediums by age and by gender and is meant to help bankers to decide the best means of reaching their intended audience.

\section{Methodology}

This paper is based on the results of a survey. Each student in a commercial banking class was tasked with administering a number of surveys to individuals of all ages. The students were instructed in the proper methodologies for confidentiality when using human test subjects. The completed surveys were collected by the class professor. In addition to information on age and gender, the survey consists of five questions about bank advertisements using different media venues. The participants were asked if they had seen banks advertised in a particular medium and, if so, did it leave a favorable or unfavorable impression. A final question asks the participants to rank the five types of advertising from most favorable to least favorable.

Responses are analyzed for the entire survey population, then, by gender, by age, and by age within each gender. Since the subsample and the population consist of different numbers of observations, we employ a Chi-square test to determine if the response frequencies of the subsets are significantly different statistically from the expected frequencies based on the overall population responses. A p-value of .10 or less indicates that the subsample frequency is different from the population frequency at a statistically significant level.

\section{Overall survey}

A total of 365 respondents participated in the survey. 187 or $51.23 \%$ were male and 178 or $48.77 \%$ were female. We had the respondents select their age range from one of four categories. $40.55 \%$ were under the age of twenty-five; $24.38 \%$ were between the ages twenty-five to thirty-five; $19.45 \%$ were between the ages thirty-six to fifty; and $15.62 \%$ were over fifty. Table 1 shows these results, as well as the responses to the questions regarding the advertising in the different media types.

\section{Table 1. Overall results}

This table shows the participation rate by gender and by age. It also shows the results for the first five questions regarding advertising in the different venues. $\mathrm{N}$ is the total number of respondents per category, and the percent is the percent of respondents per category.

\begin{tabular}{|c|c|c|c|}
\hline & & $\mathrm{N}$ & $\%$ \\
\hline \multicolumn{4}{|l|}{ Gender } \\
\hline & Male & 187 & $51.23 \%$ \\
\hline & Female & 178 & $48.77 \%$ \\
\hline \multicolumn{4}{|l|}{ Age } \\
\hline & $<25$ & 148 & $40.55 \%$ \\
\hline & $25-35$ & 89 & $24.38 \%$ \\
\hline & $36-50$ & 71 & $19.45 \%$ \\
\hline & $>50$ & 57 & $15.62 \%$ \\
\hline \multicolumn{4}{|c|}{ Type of advertising } \\
\hline \multicolumn{4}{|c|}{ Television } \\
\hline & Favorable & 160 & $43.84 \%$ \\
\hline & Unfavorable & 166 & $45.48 \%$ \\
\hline & Not seen & 39 & $10.68 \%$ \\
\hline \multicolumn{4}{|c|}{ Social media/internet } \\
\hline & Favorable & 97 & $26.58 \%$ \\
\hline & Unfavorable & 155 & $42.47 \%$ \\
\hline & Not seen & 113 & $30.96 \%$ \\
\hline \multicolumn{4}{|l|}{ Radio } \\
\hline & Favorable & 81 & $22.25 \%$ \\
\hline & Unfavorable & 128 & $35.16 \%$ \\
\hline & Not heard & 155 & $42.58 \%$ \\
\hline \multicolumn{4}{|l|}{ Billboards } \\
\hline & Favorable & 87 & $23.84 \%$ \\
\hline & Unfavorable & 153 & $41.92 \%$ \\
\hline & Not seen & 125 & $34.25 \%$ \\
\hline \multicolumn{4}{|l|}{ Print media } \\
\hline & Favorable & 97 & $26.58 \%$ \\
\hline & Unfavorable & 112 & $30.68 \%$ \\
\hline & Not seen & 156 & $42.74 \%$ \\
\hline
\end{tabular}

Advertising on television was the most effective media with bank advertising on television being seen by $89 \%$ of the survey respondents. $43.84 \%$ of the respondents found the advertising to be favorable while $45.48 \%$ found it unfavorable. Only $10.68 \%$ of the survey respondents had not seen any banks advertised on television.

Advertising on social media or the internet was the second most effective method with $69 \%$ of the respondents having seen some bank advertising in this venue. However, only $26.58 \%$ of the respondents found this to leave a favorable impression.

Billboards were the third most effective method with $65.75 \%$ having seen bank advertising on billboards. Only $23.84 \%$ found this to be a method that left a favorable impression. 
Radio and print media were very close in terms of the number of respondents that had seen or heard advertising in these venues. Both were $57 \%$ of the respondents; however, the print advertising was seen as favorable by $26.58 \%$ of the respondents, while radio advertising was only deemed favorable by $22.25 \%$ of the time.

3.1. Differences by gender. We analyze the results of the survey by gender and find that males and females react similarly in our study. Television is the most effective method of advertising followed by social media and billboards. The only significant difference in responses between genders is in the number of respondents that did not see any banks advertised on billboards. $41.57 \%$ female respondents did not see billboard advertising, while only $27.27 \%$ of male respondents did not see billboard advertising.

3.2. Differences by age. Our study shows that there are a number of statistically significant differences in advertising preferences based on age. However, television is the most effective medium in every age group. $85 \%$ to $93 \%$ of the respondents had seen bank advertising on television, which is a greater rate than any of the other four mediums. Additionally, $34 \%$ to $58 \%$ found the impact to be favorable. None of the other venues had that consistently high favorability rating across age groups. The over fifty age group responded the most favorably to television advertising with 58\% responding in the favorable category. The twenty-five to thirtyfive age group had the most unfavorable respondents at $56 \%$. Both of these deviations are statistically significant results. The results by age are shown in Table 2.

The results for social media or internet advertising were not surprising. The two younger age categories responded that they had seen bank advertising on social media at a rate of $78 \%$ to $80 \%$, while the two older age groups had only seen this type of bank advertising at a rate of $49 \%$ to $54 \%$. The twenty-five to thirty five age group found advertising on social media to be unfavorable at a rate of $54 \%$ of the time, which is significantly higher than the norm.

Billboard advertising was the third most effective means of creating awareness. $61 \%$ to $70 \%$ of respondents had seen bank advertising on billboards, however, responses to the billboard (favorable or unfavorable) varied by age. $35 \%$ of the oldest age group, over fifty found the billboard advertising to be favorable, while only $19.59 \%$ of the under twenty-five age group had a favorable response. This is a statistically significant difference. Interestingly, there is a monotonic pattern across the age groups; the percent responding with "favorable" increased as the age group increased.
Radio advertising has the lowest awareness with only $56 \%$ to $68 \%$ indicating that they have heard banks advertised on the radio. Similar to billboards, only $19.59 \%$ of the under twenty-five age group found this to leave a favorable impression, while $35 \%$ of the over fifty group found it to be favorable. This is a statistically significant difference. Again, there is a monotonic pattern across age groups where the older the age group, the more the favorable responses.

Print media, not surprisingly, has the greatest differences between age groups. Only $46.62 \%$ of the under twenty-five is aware of any bank advertising using print media. Only $16.89 \%$ of this youngest age group responded that the print-based advertising left a favorable impression. However, $77.19 \%$ of the oldest age group are aware of print-based bank advertising and $45.61 \%$ responded that it left a favorable impression. And once again, there is a monotonic pattern across the age groups. The older the age group, the more often they are aware of print based bank advertising and the greater percent of the group found that it left a favorable impression.

One overall interesting finding regarding age is that for every category, the age group with the largest number of respondents that found the advertising to leave a favorable impression is the over fifty group.

3.3. Age differences by gender. We next examine the results by age within the two gender categories to determine if males and females react differently within the different age categories. These results are shown in Table 3. There is a significant difference between males and females in the thirty-five to fifty age category with regards to their responses to television. $55.88 \%$ of women in this category find television advertising to leave a favorable impression, while only $29.73 \%$ of males in this age range find the television advertising favorable. The number of respondents who have not seen television bank advertising is also different. Only $8.82 \%$ of women in this category have not seen television advertising while $21.62 \%$ of males have not.

There are similar differences in this age category for social media and print advertising. In social media $13.51 \%$ of the males find it favorable and $51.35 \%$ have not seen any social media bank advertising, while $23.53 \%$ of females in this age category find the social media advertising to be favorable and only $41.18 \%$ have not seen any social media bank advertising. More males in this age range find print media to leave a favorable impression than females. $40.54 \%$ of males find it favorable and only $24.32 \%$ have not seen any print advertising, while $26.47 \%$ of females find the print advertising favorable and $35.29 \%$ have not seen any. 
The other age range that showed some significant differences between males and females is the over fifty age range. $60.71 \%$ of females found television advertising to be favorable and only $3.57 \%$ had not seen any television advertising. However, only $55.17 \%$ of males in this category found the television advertising to be favorable and $10.34 \%$ had not seen television advertising.

The other differences between genders in this age group are that males found radio and billboards to be more favorable than females and females found print media to be more favorable. $50 \%$ of women had not seen billboard advertising, while only $20.69 \%$ of males had not seen billboards.

\section{Rankings}

The participants were asked to rank the bank advertising that they had seen, heard, or read from 1 to 5 with 1 being the most favorable and 5 the least favorable. Overall, television advertising was rated the most favorable by $53.7 \%$ of the respondents. Television kept its spot as most favorable for both genders and for all age groups.

Social media and internet advertising had the second most votes for the "most favorable" form of advertising with $22.47 \%$ of the respondents choosing this medium. This held true for both genders and for the under twenty-five and twenty-five to thirty-five age groups. Print advertising was the second highest for the age groups thirty-six to fifty and over fifty.

Radio consistently received the fewest votes for most favorable advertising across both genders and for all age groups.
We, then, examined the "least favorable" results. Overall, the category of bank advertising with the greatest number of "least favorable" votes is the traditional print media with $34.71 \%$ of the respondents picking this. The two youngest age groups also selected print media as their least favorite form of advertising, but the two older age groups, thirty-six to fifty, and over fifty both picked social media and internet advertising as their least favorite form of bank advertising.

Billboards were the second "least favorite" form for all groups, except for the age group twenty-five to thirty-five and thirty-six to fifty who selected radio and print media, respectively.

\section{Conclusion}

Television advertising is the most effective of the media that we examine in terms of generating awareness and for generating a positive message. Not surprisingly, social media advertising works better for the younger two age groups than the older two, and print media is more popular with the older age groups. However, television remains the most favored method of advertising and whether the message is perceived favorably or unfavorably, television reaches the largest percent of the population regardless of age.

Overall, the over fifty-age group had the greatest percentage of respondents that found the advertising to leave a favorable impression regardless of the medium used. This suggests that banks may not need to change the medium, but may need a different message when attempting to appeal to the younger customers.

\section{References}

1. Editor. (2014). Can you increase core deposits without extensive advertising. ABA Marketing \& Sales Journal, Dec., 46(10), 6.

2. Cook, G. (2011). Driven to differentiate, Independent Banker, Jan., 56-61.

3. Franzen, G., and S. Moriarty. (2009). The Science and Art of Branding. M. E. Sharpe, New York.

4. Mac Gregor, T. D. (1913). Bank Advertising Plan. Bankers Publishing Co., Boston.

5. Morrall, K. (1995). New twists in image campaigns. Bank Marketing, Apr., 27, 49-55.

6. Nelson-Field, K., E. Riebe, and B. Sharp (2012). What's not to "like"? Can a Facebook fan base give a brand the advertising reach it needs? Journal of Advertising Research, 52(2), 262-69.

7. Nielsen. (2012). Global Trust in advertising and Brand Managers, Nielsen, 1-5. Retrieved from http://www.nielsen.com/us/en/press-room/2012/nielsen-global-consumers-trust-in-earned-advertisinggrows.html (February 1, 2016).

8. Nielsen. (2015). Millennials are most trusting when it comes to advertising. Nielsen, 1-7. Retrieved from http://www.nielsen.com/us/en/insights/news/2015/millennials-are-most-trusting-when-it-comes-to-advertising.html (February 1, 2016).

9. Schultz, D. (2014). Reaching for what? Marketing Insights, May/June, 14-15.

10. Sharp, B. (2010). How Brands Grow: What marketers don't know? Oxford University Press, New York. 
Appendix 1

Table 2. Age

This table shows the overall results and the results by age to questions $1-5$ on the survey. Participants were asked if they had seen or heard bank advertising in the stated medium and if so if it left a favorable or unfavorable impression. The table shows the total number of respondents for each category per question and the percent. The number in the parenthesis is the probability that the percentage responses are statistically significantly different from the overall survey responses based on a Chi-square statistic. One asterisk indicates significance at the $10 \%$ level, two asterisks at the 5\% level, and 3 asterisks within the $1 \%$ level.

\begin{tabular}{|c|c|c|c|c|c|c|c|}
\hline & & & All & & ss than 25 & & 5 to 35 \\
\hline \multicolumn{8}{|l|}{ Television } \\
\hline & Favorable & 160 & $43.84 \%$ & 67 & $45.27 \%$ & 30 & $33.71 \%$ \\
\hline & & & & & $(0.7669)$ & & $(0.0825)^{*}$ \\
\hline & Unfavorable & 166 & $45.48 \%$ & 66 & $44.59 \%$ & 50 & $56.18 \%$ \\
\hline & & & & & $(0.8552)$ & & $(0.0699)^{*}$ \\
\hline & Not seen & 39 & $10.68 \%$ & 15 & $10.14 \%$ & 9 & $10.11 \%$ \\
\hline & & & & & $(0.8541)$ & & $(0.8748)$ \\
\hline \multicolumn{8}{|c|}{ Social media/internet } \\
\hline & Favorable & 97 & $26.58 \%$ & 44 & $29.73 \%$ & 23 & $25.84 \%$ \\
\hline & & & & & $(0.4684)$ & & $(0.8882)$ \\
\hline & Unfavorable & 155 & $42.47 \%$ & 71 & $47.97 \%$ & 48 & $53.93 \%$ \\
\hline & & & & & $(0.2550)$ & & $(0.0511)^{*}$ \\
\hline & Not seen & 113 & $30.96 \%$ & 33 & $22.30 \%$ & 18 & $20.22 \%$ \\
\hline & & & & & $(0.0489)^{*}$ & & $(0.0451)^{*}$ \\
\hline \multicolumn{8}{|l|}{ Radio } \\
\hline & Favorable & 81 & $22.25 \%$ & 26 & $17.69 \%$ & 18 & $20.22 \%$ \\
\hline & & & & & $(0.2509)$ & & $(0.6781)$ \\
\hline & Unfavorable & 128 & $35.16 \%$ & 56 & $38.10 \%$ & 27 & $30.34 \%$ \\
\hline & & & & & $(0.5322)$ & & $(0.3895)$ \\
\hline & Not heard & 155 & $42.58 \%$ & 65 & $44.22 \%$ & 44 & $49.44 \%$ \\
\hline & & & & & $(0.7354)$ & & $(0.2427)$ \\
\hline \multicolumn{8}{|l|}{ Billboards } \\
\hline & Favorable & 87 & $23.84 \%$ & 29 & $19.59 \%$ & 19 & $21.35 \%$ \\
\hline & & & & & $(0.2982)$ & & $(0.6189)$ \\
\hline & Unfavorable & 153 & $41.92 \%$ & 70 & $47.30 \%$ & 35 & $39.33 \%$ \\
\hline & & & & & $(0.2655)$ & & $(0.6562)$ \\
\hline & Not seen & 125 & $34.25 \%$ & 49 & $33.11 \%$ & 35 & $39.33 \%$ \\
\hline & & & & & $(0.8051)$ & & $(0.3685)$ \\
\hline \multicolumn{8}{|l|}{ Print media } \\
\hline & Favorable & 97 & $26.58 \%$ & 25 & $16.89 \%$ & 22 & $24.72 \%$ \\
\hline & & & & & $(0.0196)^{* *}$ & & $(0.7211)$ \\
\hline & Unfavorable & 112 & $30.68 \%$ & 44 & $29.73 \%$ & 24 & $26.97 \%$ \\
\hline & & & & & $(0.8313)$ & & $(0.4923)$ \\
\hline & Not seen & 156 & $42.74 \%$ & 79 & $53.38 \%$ & 43 & $48.31 \%$ \\
\hline & & & & & $(0.0284)$ ** & & -0.3419 \\
\hline
\end{tabular}

Table 2 (cont.). Age

This table shows the overall results and the results by age to questions $1-5$ on the survey. Participants were asked if they had seen or heard bank advertising in the stated medium and if so if it left a favorable or unfavorable impression. The table shows the total number of respondents for each category per question and the percent. The number in the parenthesis is the probability that the percentage responses are statistically significantly different from the overall survey responses based on a Chi-square statistic. One asterisk indicates significance at the $10 \%$ level, two asterisks at the $5 \%$ level, and 3 asterisks within the $1 \%$ level.

\begin{tabular}{|c|c|c|c|c|c|c|c|}
\hline & & & All & & 36 to 50 & & Over 50 \\
\hline \multicolumn{8}{|l|}{ Television } \\
\hline & Favorable & 160 & $43.84 \%$ & 30 & $42.25 \%$ & 33 & $57.89 \%$ \\
\hline & & & & & $(0.8057)$ & & $(0.0475)^{* *}$ \\
\hline & Unfavorable & 166 & $45.48 \%$ & 30 & $42.25 \%$ & 20 & $35.09 \%$ \\
\hline & & & & & $(0.6171)$ & & $(0.1417)$ \\
\hline & Not seen & 39 & $10.68 \%$ & 11 & $15.49 \%$ & 4 & $7.02 \%$ \\
\hline & & & & & $(0.2447)$ & & $(0.3946)$ \\
\hline \multicolumn{8}{|c|}{ Social media/internet } \\
\hline & Favorable & 97 & $26.58 \%$ & 13 & $18.31 \%$ & 17 & $29.82 \%$ \\
\hline & & & & & $(0.1423)$ & & $(0.6074)$ \\
\hline & Unfavorable & 155 & $42.47 \%$ & 25 & $35.21 \%$ & 11 & $19.30 \%$ \\
\hline & & & & & $(0.2560)$ & & $(0.0009)^{* * *}$ \\
\hline & Not seen & 113 & $30.96 \%$ & 33 & $46.48 \%$ & 29 & $50.88 \%$ \\
\hline & & & & & $(0.0112)^{* *}$ & & $(0.0031)^{* * *}$ \\
\hline \multicolumn{8}{|l|}{ Radio } \\
\hline & Favorable & 81 & $22.25 \%$ & 17 & $23.94 \%$ & 20 & $35.09 \%$ \\
\hline & & & & & $(0.7551)$ & & $(0.0349)^{* *}$ \\
\hline & Unfavorable & 128 & $35.16 \%$ & 31 & $43.66 \%$ & 14 & $24.56 \%$ \\
\hline & & & & & $(0.1738)$ & & $(0.1154)$ \\
\hline & Not heard & 155 & $42.58 \%$ & 23 & $32.39 \%$ & 23 & $40.35 \%$ \\
\hline & & & & & $(0.1102)$ & & $(0.7512)$ \\
\hline \multicolumn{8}{|l|}{ Billboards } \\
\hline & Favorable & 87 & $23.84 \%$ & 19 & $26.76 \%$ & 20 & $35.09 \%$ \\
\hline & & & & & $(0.5991)$ & & $(0.0694)^{*}$ \\
\hline & Unfavorable & 153 & $41.92 \%$ & 31 & $43.66 \%$ & 17 & $29.82 \%$ \\
\hline & & & & & $(0.7854)$ & & $(0.0834)^{*}$ \\
\hline & Not seen & 125 & $34.25 \%$ & 21 & $29.58 \%$ & 20 & $35.09 \%$ \\
\hline & & & & & $(0.4456)$ & & $(0.9010)$ \\
\hline \multicolumn{8}{|l|}{ Print media } \\
\hline & Favorable & 97 & $26.58 \%$ & 24 & $33.80 \%$ & 26 & $45.61 \%$ \\
\hline & & & & & $(0.2134)$ & & $(0.0033)^{* * *}$ \\
\hline & Unfavorable & 112 & $30.68 \%$ & 26 & $36.62 \%$ & 18 & $31.58 \%$ \\
\hline & & & & & $(0.3252)$ & & $(0.8919)$ \\
\hline & Not seen & 156 & $42.74 \%$ & 21 & $29.58 \%$ & 13 & $22.81 \%$ \\
\hline & & & & & $(0.0388)^{* *}$ & & $(0.0043)^{\star \star \star}$ \\
\hline
\end{tabular}


Table 3. Compare male and female by age

This table shows the overall results and the results by gender for specific age groups that had significant differences. The table shows the total number of respondents for each category per question and the percent. The number in the parenthesis is the probability that the percentage responses are statistically significantly different from the overall survey responses based on a Chi-square statistic. One asterisk indicates significance at the $10 \%$ level, two asterisks at the $5 \%$ level and 3 asterisks within the $1 \%$ level.

\begin{tabular}{|c|c|c|c|c|c|c|c|}
\hline \multirow{2}{*}{ Televisio } & & \multicolumn{2}{|r|}{ All } & \multicolumn{2}{|c|}{ Female $<25$} & \multicolumn{2}{|c|}{ Male $<25$} \\
\hline & & & & & & & \\
\hline & 160 & $43.84 \%$ & 34 & $43.04 \%$ & & $47.83 \%$ \\
\hline & & & & & $(0.8969)$ & & $(0.5407)$ \\
\hline & Unfavorable & 166 & $45.48 \%$ & 38 & $48.10 \%$ & 28 & $40.58 \%$ \\
\hline & & & & & $(0.6716)$ & & $(0.4528)$ \\
\hline & Not seen & 39 & $10.68 \%$ & 7 & $8.86 \%$ & 8 & $11.59 \%$ \\
\hline & & & & & (0.6295) & & $(0.8326)$ \\
\hline \multicolumn{8}{|c|}{ Social media/internet } \\
\hline & Favorable & 97 & $26.58 \%$ & 26 & $32.91 \%$ & 18 & $26.09 \%$ \\
\hline & & & & & $(0.2539)$ & & $(0.9328)$ \\
\hline & Unfavorable & 155 & $42.47 \%$ & 36 & $45.57 \%$ & 35 & $50.72 \%$ \\
\hline & & & & & $(0.6134)$ & & $(0.2047)$ \\
\hline & Not seen & 113 & $30.96 \%$ & 17 & $21.52 \%$ & 16 & $23.19 \%$ \\
\hline & & & & & $(0.0946)^{*}$ & & $(0.1953)$ \\
\hline \multicolumn{8}{|l|}{ Radio } \\
\hline & Favorable & 81 & $22.25 \%$ & 14 & $17.72 \%$ & 12 & $17.65 \%$ \\
\hline & & & & & $(0.3738)$ & & $(0.3963)$ \\
\hline & Unfavorable & 128 & $35.16 \%$ & 30 & $37.97 \%$ & 26 & $38.24 \%$ \\
\hline & & & & & $(0.6365)$ & & $(0.6275)$ \\
\hline & Not heard & 155 & $42.58 \%$ & 35 & $44.30 \%$ & 30 & $44.12 \%$ \\
\hline & & & & & $(0.7793)$ & & $(0.8143)$ \\
\hline \multicolumn{8}{|c|}{ Billboards } \\
\hline & Favorable & 87 & $23.84 \%$ & 9 & $11.39 \%$ & 20 & $28.99 \%$ \\
\hline & & & & & $(0.0149)^{* *}$ & & $(0.3627)$ \\
\hline & Unfavorable & 153 & $41.92 \%$ & 39 & $49.37 \%$ & 31 & $44.93 \%$ \\
\hline & & & & & $(0.2256)$ & & $(0.6427)$ \\
\hline & Not seen & 125 & $34.25 \%$ & 31 & $39.24 \%$ & 18 & $26.09 \%$ \\
\hline & & & & & $(0.3992)$ & & $(0.1860)$ \\
\hline \multicolumn{8}{|c|}{ Print media } \\
\hline & Favorable & 97 & $26.58 \%$ & 13 & $16.46 \%$ & 12 & $17.39 \%$ \\
\hline & & & & & $(0.0589)^{*}$ & & $(0.1067)$ \\
\hline & Unfavorable & 112 & $30.68 \%$ & 24 & $30.38 \%$ & 20 & $28.99 \%$ \\
\hline & & & & & $(0.9574)$ & & $(0.7784)$ \\
\hline & Not seen & 156 & $42.74 \%$ & 42 & $53.16 \%$ & 37 & $53.62 \%$ \\
\hline & & & & & $(0.0910)^{*}$ & & $(0.0952)^{*}$ \\
\hline
\end{tabular}

Table 3 (cont.). Compare male and female by age

This table shows the overall results and the results by gender for specific age groups that had significant differences. The table shows the total number of respondents for each category per question and the percent. The number in the parenthesis is the probability that the percentage responses are statistically significantly different from the overall survey responses based on a Chi-square statistic. One asterisk indicates significance at the $10 \%$ level, two asterisks at the $5 \%$ level and 3 asterisks within the $1 \%$ level.

\begin{tabular}{|c|c|c|c|c|c|c|c|}
\hline \multirow{2}{*}{\multicolumn{2}{|c|}{$\begin{array}{l} \\
\text { Television }\end{array}$}} & \multicolumn{2}{|r|}{ All } & \multicolumn{2}{|c|}{ Females 25 to 35} & \multicolumn{2}{|c|}{ Males 25 to 35} \\
\hline & \\
\hline & Favorable & 160 & \begin{tabular}{|l|}
$43.84 \%$ \\
\end{tabular} & 11 & $29.73 \%$ & 19 & $36.54 \%$ \\
\hline & & & & & $(0.0982)$ & & $(0.3199)$ \\
\hline & Unfavorable & 166 & $45.48 \%$ & 21 & $56.76 \%$ & 29 & $55.77 \%$ \\
\hline & & & & & $(0.1900)$ & & $(0.1641)$ \\
\hline & Not seen & 39 & $10.68 \%$ & 5 & $13.51 \%$ & 4 & $7.69 \%$ \\
\hline & & & & & $(0.5995)$ & & $(0.5068)$ \\
\hline \multicolumn{8}{|c|}{ Social media/internet } \\
\hline & Favorable & 97 & $26.58 \%$ & 6 & $16.22 \%$ & 17 & $32.69 \%$ \\
\hline & & & & & $(0.1690)$ & & $(0.3545)$ \\
\hline & Unfavorable & 155 & $42.47 \%$ & 22 & $59.46 \%$ & 26 & $50.00 \%$ \\
\hline & & & & & $(0.0472)$ ** & & $(0.3051)$ \\
\hline & Not seen & 113 & $30.96 \%$ & 9 & $24.32 \%$ & 9 & $17.31 \%$ \\
\hline & & & & & $(0.4029)$ & & $(0.0429)^{* *}$ \\
\hline \multicolumn{8}{|l|}{ Radio } \\
\hline & Favorable & 81 & $22.25 \%$ & 7 & $18.92 \%$ & 11 & $21.15 \%$ \\
\hline & & & & & $(0.6406)$ & & $(0.8582)$ \\
\hline & Unfavorable & 128 & $35.16 \%$ & 9 & $24.32 \%$ & 18 & $34.62 \%$ \\
\hline & & & & & $(0.1853)$ & & $(0.9381)$ \\
\hline & Not heard & 155 & $42.58 \%$ & 21 & $56.76 \%$ & 23 & $44.23 \%$ \\
\hline & & & & & $(0.0979)^{*}$ & & $(0.8222)$ \\
\hline \multicolumn{8}{|c|}{ Billboards } \\
\hline & Favorable & 87 & $23.84 \%$ & 7 & $18.92 \%$ & 12 & $23.08 \%$ \\
\hline & & & & & $(0.5008)$ & & $(0.9042)$ \\
\hline & Unfavorable & 153 & $41.92 \%$ & 11 & $29.73 \%$ & 24 & $46.15 \%$ \\
\hline & & & & & $(0.1506)$ & & $(0.5631)$ \\
\hline & Not seen & 125 & $34.25 \%$ & 19 & $51.35 \%$ & 16 & $30.77 \%$ \\
\hline & & & & & $(0.0387)^{* *}$ & & $(0.6200)$ \\
\hline \multicolumn{8}{|c|}{ Print media } \\
\hline & Favorable & 97 & $26.58 \%$ & 13 & $35.14 \%$ & 9 & $17.31 \%$ \\
\hline & & & & & $(0.2658)$ & & $(0.1510)$ \\
\hline & Unfavorable & 112 & $30.68 \%$ & 7 & $18.92 \%$ & 17 & $32.69 \%$ \\
\hline & & & & & $(0.1352)$ & & $(0.7695)$ \\
\hline & Not seen & 156 & $42.74 \%$ & 17 & $45.95 \%$ & 26 & $50.00 \%$ \\
\hline & & & & & $(0.7074)$ & & $(0.3233)$ \\
\hline
\end{tabular}


Table 3 (cont.). Compare male and female by age

This table shows the overall results and the results by gender for specific age groups that had significant differences. The table shows the total number of respondents for each category per question and the percent. The number in the parenthesis is the probability that the percentage responses are statistically significantly different from the overall survey responses based on a Chi-square statistic. One asterisk indicates significance at the $10 \%$ level, two asterisks at the $5 \%$ level and 3 asterisks within the $1 \%$ level.

\begin{tabular}{|c|c|c|c|c|c|c|c|}
\hline & & & All & \multicolumn{2}{|c|}{ Female 36 to 50} & \multicolumn{2}{|c|}{ Male 36 to 50} \\
\hline \multicolumn{8}{|c|}{ Television } \\
\hline & Favorable & 160 & $43.84 \%$ & 19 & $55.88 \%$ & 11 & $29.73 \%$ \\
\hline & & & & & $(0.1767)$ & & $(0.0982)$ * \\
\hline & Unfavorable & 166 & $45.48 \%$ & 12 & $35.29 \%$ & 18 & $48.65 \%$ \\
\hline & & & & & $(0.2532)$ & & $(0.7124)$ \\
\hline & Not seen & 39 & $10.68 \%$ & 3 & $8.82 \%$ & 8 & $21.62 \%$ \\
\hline & & & & & $(0.7352)$ & & $(0.0485)^{* *}$ \\
\hline \multicolumn{8}{|c|}{ Social Media/Internet } \\
\hline & Favorable & 97 & $26.58 \%$ & 8 & $23.53 \%$ & 5 & $13.51 \%$ \\
\hline & & & & & $(0.6997)$ & & $(0.0819)^{*}$ \\
\hline & Unfavorable & 155 & $42.47 \%$ & 12 & $35.29 \%$ & 13 & $35.14 \%$ \\
\hline & & & & & $(0.4175)$ & & $(0.3890)$ \\
\hline & Not seen & 113 & $30.96 \%$ & 14 & $41.18 \%$ & 19 & $51.35 \%$ \\
\hline & & & & & $(0.2212)$ & & $(0.0118)^{* *}$ \\
\hline \multicolumn{8}{|l|}{ Radio } \\
\hline & Favorable & 81 & $22.25 \%$ & 8 & $23.53 \%$ & 9 & $24.32 \%$ \\
\hline & & & & & $(0.8643)$ & & $(0.7735)$ \\
\hline & Unfavorable & 128 & $35.16 \%$ & 16 & $47.06 \%$ & 15 & $40.54 \%$ \\
\hline & & & & & $(0.1675)$ & & $(0.5154)$ \\
\hline & Not heard & 155 & $42.58 \%$ & 10 & $29.41 \%$ & 13 & $35.14 \%$ \\
\hline & & & & & $(0.1360)$ & & $(0.3817)$ \\
\hline \multicolumn{8}{|c|}{ Billboards } \\
\hline & Favorable & 87 & $23.84 \%$ & 11 & $32.35 \%$ & 8 & $21.62 \%$ \\
\hline & & & & & $(0.2698)$ & & $(0.7626)$ \\
\hline & Unfavorable & 153 & $41.92 \%$ & 13 & $38.24 \%$ & 18 & $48.65 \%$ \\
\hline & & & & & $(0.6769)$ & & $(0.4301)$ \\
\hline & Not seen & 125 & $34.25 \%$ & 10 & $29.41 \%$ & 11 & $29.73 \%$ \\
\hline & & & & & $(0.5688)$ & & $(0.5800)$ \\
\hline \multicolumn{8}{|c|}{ Print Media } \\
\hline & Favorable & 97 & $26.58 \%$ & 9 & $26.47 \%$ & 15 & $40.54 \%$ \\
\hline & & & & & $(0.9894)$ & & $(0.0710)^{*}$ \\
\hline & Unfavorable & 112 & $30.68 \%$ & 13 & $38.24 \%$ & 13 & $35.14 \%$ \\
\hline & & & & & $(0.3640)$ & & $(0.5774)$ \\
\hline & Not seen & 156 & $42.74 \%$ & 12 & $35.29 \%$ & 9 & $24.32 \%$ \\
\hline & & & & & $(0.4003)$ & & $(0.0300)$ ** \\
\hline
\end{tabular}

Table 3 (cont.). Compare male and female by age

This table shows the overall results and the results by gender for specific age groups that had significant differences. The table shows the total number of respondents for each category per question and the percent. The number in the parenthesis is the probability that the percentage responses are statistically significantly different from the overall survey responses based on a Chi-square statistic. One asterisk indicates significance at the $10 \%$ level, two asterisks at the $5 \%$ level and 3 asterisks within the $1 \%$ level.

\begin{tabular}{|c|c|c|c|c|c|c|}
\hline \multirow{2}{*}{\begin{tabular}{|l} 
Television \\
\end{tabular}} & \multicolumn{2}{|r|}{ All } & \multicolumn{2}{|c|}{ Female Over 50} & \multicolumn{2}{|c|}{ Male Over 50} \\
\hline & & & & & & \\
\hline \begin{tabular}{l|l|} 
& Favorable
\end{tabular} & 160 & $43.84 \%$ & 17 & $60.71 \%$ & 16 & $55.17 \%$ \\
\hline & & & & $(0.0836)^{*}$ & & $(0.2372)$ \\
\hline Unfavorable & 166 & $45.48 \%$ & 10 & $35.71 \%$ & 10 & $34.48 \%$ \\
\hline & & & & $(0.3166)$ & & $(0.2516)$ \\
\hline Not seen & 39 & $10.68 \%$ & 1 & $3.57 \%$ & 3 & $10.34 \%$ \\
\hline & & & & $(0.2302)$ & & $(0.9544)$ \\
\hline \multicolumn{7}{|l|}{ Social Media/Internet } \\
\hline Favorable & 97 & $26.58 \%$ & 8 & $28.57 \%$ & 9 & $31.03 \%$ \\
\hline & & & & $(0.8181)$ & & $(0.6022)$ \\
\hline Unfavorable & 155 & $42.47 \%$ & 6 & $21.43 \%$ & 5 & $17.24 \%$ \\
\hline & & & & $(0.0291)^{* \star}$ & & $(0.0078)^{* * *}$ \\
\hline Not seen & 113 & $30.96 \%$ & 14 & $50.00 \%$ & 15 & $51.72 \%$ \\
\hline & & & & $(0.0379)^{* *}$ & & $(0.0216)^{* *}$ \\
\hline \multicolumn{7}{|l|}{ Radio } \\
\hline Favorable & 81 & $22.25 \%$ & 8 & $28.57 \%$ & 12 & $41.38 \%$ \\
\hline & & & & $(0.4418)$ & & $(0.0197)^{* *}$ \\
\hline Unfavorable & 128 & $35.16 \%$ & 7 & $25.00 \%$ & 7 & $24.14 \%$ \\
\hline & & & & $(0.2754)$ & & $(0.2288)$ \\
\hline Not heard & 155 & $42.58 \%$ & 13 & $46.43 \%$ & 10 & $34.48 \%$ \\
\hline & & & & (0.6919) & & $(0.3950)$ \\
\hline \multicolumn{7}{|l|}{ Billboards } \\
\hline \begin{tabular}{l|l|} 
& Favorable \\
\end{tabular} & 87 & $23.84 \%$ & 8 & $28.57 \%$ & 12 & $41.38 \%$ \\
\hline & & & & $(0.5727)$ & & $(0.0360)^{* *}$ \\
\hline Unfavorable & 153 & $41.92 \%$ & 6 & $21.43 \%$ & 11 & $37.93 \%$ \\
\hline & & & & $(0.0333)^{* *}$ & & $(0.6751)$ \\
\hline Not seen & 125 & $34.25 \%$ & 14 & $50.00 \%$ & 6 & $20.69 \%$ \\
\hline & & & & $(0.0929)$ * & & $(0.1358)$ \\
\hline \multicolumn{7}{|l|}{ Print Media } \\
\hline Favorable & 97 & $26.58 \%$ & 15 & $53.57 \%$ & 11 & $37.93 \%$ \\
\hline & & & & $(0.0023)^{* \star \star}$ & & $(0.1870)$ \\
\hline Unfavorable & 112 & $30.68 \%$ & 7 & $25.00 \%$ & 11 & $37.93 \%$ \\
\hline & & & & $(0.5281)$ & & $(0.4176)$ \\
\hline Not seen & 156 & $42.74 \%$ & 6 & $21.43 \%$ & 7 & $24.14 \%$ \\
\hline & & & & $(0.0273)^{* \star}$ & & $(0.0503)^{*}$ \\
\hline
\end{tabular}




\section{Appendix 2}

\section{QUESTIONNAIRE}

\section{BANK ADVERTISING AWARENESS}

We respect your privacy and do not want you to put your name on this form nor does it involve any purchase or obligation on your part. Your responses will be very helpful in a research project. Please take a few minutes to respond to the following questions by placing an " $\mathrm{X}$ " following the appropriate answer in questions 1 through 5, and for question 6 , please rank the items in terms of importance to you.

Sex: Female Male

Age group: Under 25 years of age 25 to 35 36 to 50 Over 50 years of age

1. Have you seen advertisements for banks on television? (Check only one)
a. YES, and it made a favorable impression on me.
b. YES, but I was not favorably impress by it.
c. NO, I have not seen advertisements for banks on television.

2. Have you seen advertisements for banks on social media or internet? (Check only one)
a. YES, and it made a favorable impression on me.
b. YES, but I was not favorably impress by it.
c. NO, I have not seen advertisements for banks on social media.

3. Have you heard advertisements for banks on the radio? (Check only one)
a. YES, and it made a favorable impression on me.
b. YES, but I was not favorably impress by it.
c. $\quad \mathrm{NO}$, I have not seen advertisements for banks on radio.

4. Have you seen any billboards advertising banks? (Check only one)
a. $\quad$ YES, and it made a favorable impression on me.
b. YES, but I was not favorably impress by it.
c. _ NO, I have not seen advertisements for banks on billboards.

5. Have you seen advertisements for banks in a newspaper or magazine? (Check only one)
a. YES, and it made a favorable impression on me.
b. Y YES, but I was not favorably impress by it.
c. _ NO, I have not seen advertisements for banks in a newspaper or magazine.

6. Taking into account all of the bank advertising you have viewed, heard, or read, please rank them in order 1 through 5, with 1 being most favorable and 5 being the least favorable.
a. Television
b. Social media or internet
c. Radio
d. Billboards
e. Newspapers or magazines

THANK YOU FOR TAKING TIME TO ASSIST US WITH OUR RESEARCH. 